\title{
Sessions 3 and 8: Pretreatment and Biomass Recalcitrance: Fundamentals and Progress
}

\author{
Y.-H. Percival Zhang • Eric Berson • Simo Sarkanen • \\ Bruce E. Dale
}

Published online: 26 March 2009

(C) Humana Press 2009

Overcoming lignocellulosic biomass recalcitrance followed by enzymatic hydrolysis of structural polymeric carbohydrates (i.e., cost-efficient liberation of fermentable sugars) is perhaps the most challenging technical and economic barrier to success of biorefineries [1-3]. Lignocellulosic biomass is a natural composite having three main biopolymers (cellulose, hemicellulose, and lignin) intertwined chemically and physically. The central role of biomass pretreatment has been indicated by the fact that 12 oral presentations and 76 posters were given on the subject at this symposium. Pretreatment is among the most costly steps in biochemical conversion of biomass [4, 5], accounting for up to $40 \%$ of the total processing cost [6]. Also, it affects the costs of other operations including size reduction prior to pretreatment and enzymatic hydrolysis and fermentation after pretreatment. Pretreatment can also strongly influence downstream costs involving detoxification if inhibitors were generated, enzymatic hydrolysis rate and enzyme loading, mixing power, product concentration, product purification, power generation, waste treatment demands, and other process variables [4].

Although a number of pretreatment methods have been proposed and investigated on the laboratory scale and even pilot plant scale during the past several decades, much of the data in the literature have been obtained and reported under different standards, leading to confusion on the part of academic researchers and potential industrial investors alike. In order to address and resolve this confusion, Prof. Bruce Dale of Michigan State University gave a brief opening to both sessions entitled "Raising the Bar for Pretreatment Research." Since overall sugar yields are one of the most important factors for the evaluation of

Y.-H. Percival Zhang $(\bowtie)$

Virginia Tech, Blacksburg, VA, USA

e-mail: ypzhang@vt.edu

E. Berson

University of Louisville, Louisville, KY, USA

S. Sarkanen

University of Minnesota, St. Paul, MN, USA

B. E. Dale

Michigan State University, East Lansing, MI, USA

濨 Humana Press 
pretreatment and hydrolysis, it is time for researchers to present mass balance and sugar yields for any biomass pretreatment, as shown in Fig. 1. The mass balance starts with $100 \mathrm{~g}$ of dry, untreated biomass, whose carbohydrate and lignin components can be determined based on the National Renewable Energy Laboratory quantitative saccharification (QS) protocol [7]. Acid-labile xylan composition can be more accurately measured by the modified QS where $1 \%$ sulfuric acid at $121^{\circ} \mathrm{C}$ for $1 \mathrm{~h}$ was used to convert all xylooligosaccharides to monomeric xylose with much less degradation [8]. All sugar compositions in two liquid streams (2 and 5) are recommended to be presented as monomeric sugar equivalents. All sugar compositions in three solid phases are recommended to be presented in the form of polymeric sugars. After most pretreatments, there are two streams - the pretreated solid biomass and the liquid hydrolysate. The carbohydrate and lignin composition of the pretreated biomass have been measured again in terms of grams in the original $100 \mathrm{~g}$ of untreated biomass. Since the hydrolysate containing monomeric sugars (e.g., glucose and xylose) and soluble oligosaccharides (e.g., cellodextrins and xylooligosaccharides) cannot be measured by one column of highperformance liquid chromatography (HPLC) at the same time, the post hydrolysis step must be conducted for converting all oligosaccharides to their respective monomeric sugars. The post hydrolysis of all oligosaccharides can be conducted in the presence of $4 \%$ sulfuric acid at $121^{\circ} \mathrm{C}$ for $1 \mathrm{~h}$ and the degradation of acid-labile sugars during post hydrolysis must been adjusted [8]. For comparative studies in the laboratory, the Biomass Refining Consortium for Applied Fundamentals and Innovation (CAFI) has recommended the enzymatic hydrolysis condition that $1 \%$ glucan is used and cellulase loading is based on filter paper units and grams of cellulase protein per gram of glucan is used at $50^{\circ} \mathrm{C}$ and $\sim 180 \mathrm{rpm}$ [9].

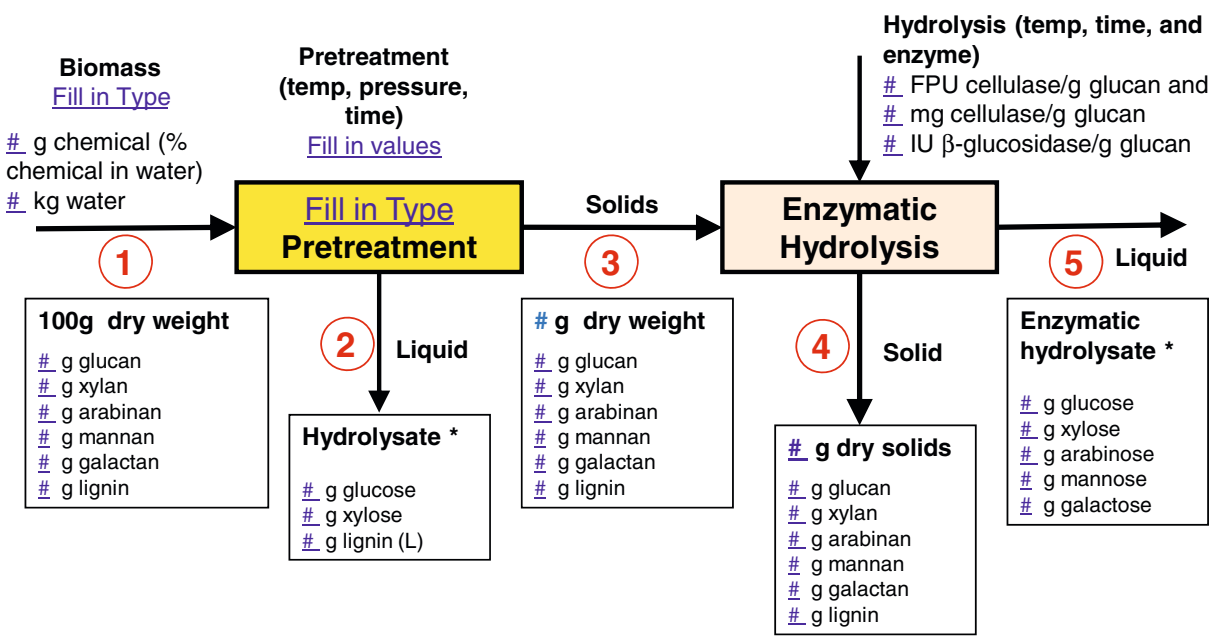

Fig. 1 Material balance flow diagram for pretreatment and enzymatic hydrolysis. The starting basis is $100 \mathrm{~g}$ of dry, untreated biomass. Mass amounts of soluble sugars (including monosaccharides and oligosaccharides) in streams 2 and 5 are presented on the basis of monomeric sugars (e.g., glucose, xylose, and mannose). Mass amounts of insoluble polysaccharides in streams 1, 3, and 4 are presented on the basis of polymeric sugars (e.g., glucan, xylan, and mannan). Cellulase enzymes used are presented on the basis of both filter paper units per gram of glucan and gram of cellulase protein per gram of glucan. In general, Trichoderma cellulase has a specific filter paper activity from $\sim 600$ to 1,500 per gram of protein $[15,16]$ 
The overall glucose yield $\left(Y_{\mathrm{Glu}}\right)$ during the pretreatment and enzymatic cellulose hydrolysis is:

$$
Y_{\mathrm{Glu}}=\frac{\mathrm{Glu}_{2}+\mathrm{Glu}_{5}}{(180 / 162) \times \mathrm{Glu}_{1}} \times 100 \%
$$

where $\mathrm{Glu}_{2}$ and $\mathrm{Glu}_{5}$ are mass amounts of glucose equivalent in streams 2 and 5 , respectively; $\mathrm{Glu}_{1}$ is the initial glucan mass amount in $100 \mathrm{~g}$ of dry biomass; and (180/162) is a correction coefficient between molecular weights of glucan and glucose equivalent. It is worth noting that commercial cellulase and beta-glucosidase solutions contain a very high concentration of sugars ( 20 up to $100 \mathrm{~g}$ glucose per liter of enzyme solution). Therefore, the glucose concentration in stream 5 should be reduced by the amount of sugars from the enzyme solutions [10].

Similarly, the overall xylose yield $\left(Y_{\mathrm{Xyl}}\right)$ is:

$$
Y_{\mathrm{Xyl}}=\frac{\mathrm{Xyl}_{2}+\mathrm{Xly}_{5}}{(150 / 132) \times \mathrm{Xyl}_{1}} \times 100 \%
$$

where $\mathrm{Xyl}_{2}$ and $\mathrm{Xyl}_{5}$ are mass amount of glucose equivalent in streams 2 and 5 , respectively; $\mathrm{Xyl}_{1}$ is the initial glucan mass amount in $100 \mathrm{~g}$ of dry biomass; and (150/132) is a correction coefficient between molecular weights of xylan and xylose equivalent.

Since a significant amount of xylooligosaccharides that cannot be measured by HPLC could exist in stream 5, the overall yield $Y_{\mathrm{Xyl}}$ can be calculated in an alternative way as below:

$$
Y_{\mathrm{Xyl}}=\frac{\mathrm{Xyl}_{2}+(150 / 132) \times\left(\mathrm{Xly}_{3}-\mathrm{Xly}_{4}\right)}{(150 / 132) \times \mathrm{Xyl}_{1}} \times 100 \%
$$

where $\mathrm{Xyl}_{3}$ and $\mathrm{Xyl}_{4}$ are the mass amounts of xylan in streams 3 and 4, respectively. Recently, several papers have been published containing material mass balances for the pretreatment and enzymatic hydrolysis steps [11, 12].

Prof. Charles E. Wyman of the University of California, Riverside gave an oral presentation pertaining to research-in-progress by the CAFI. This joint project studied the effects of the leading pretreatment technologies, such as dilute acid, ammonia fiber expansion, hot water, ammonia recycle percolation, and lime on poplar wood; the analysis covered sugar recovery, fermentation performance; and cost estimates included processing costs and capital investments.

The oral presentation was given by Noppadon Sathitsuksanoh of Virginia Tech pertaining to optimization of switchgrass pretreatment conditions for cellulose- and organic-solvent-based lignocellulose fractionation (COSLIF) for low-cellulase hydrolysis. COSLIF has been developed featuring modest reaction conditions [13]. More than $93 \%$ of glucan digestibility was obtained for COSLIF-pretreated switchgrass at a low enzyme loading of five filter paper units gram glucan in $24 \mathrm{~h}$. Supramolecular structures elucidated by scanning electron microscopy clearly show that COSLIF can completely destroy biomass recalcitrant structures [11]. Also, quantitative cellulose accessibility to enzyme measured by adsorption of a nonhydrolytic protein [14] showed that COSLIF increase substrate accessibility to enzyme two times more than did dilute acid pretreatment.

Dr. Junyong Zhu of the United States Department of Agriculture Forest Products Laboratory has developed the sulfite pretreatment to overcome recalcitrance of lignocellulose (SPORL) for softwoods, i.e., spruce and red pine, under conditions of $180^{\circ} \mathrm{C}$ for $30 \mathrm{~min}$. After pretreatment, about $10 \%$ of glucan was removed while nearly all hemicellulose was 
removed. Over $90 \%$ enzymatic cellulose conversion of pretreated substrates was achieved at an enzyme loading of 30 filter paper units cellulase per gram of glucan in $48 \mathrm{~h}$. This pretreatment was directly applied to large-sized wood chips so that the energy consumption for wood size reduction was decreased to about $20 \mathrm{~W} \mathrm{~h} / \mathrm{kg}$ of dry wood. SPORL was found to be equally effective when applied to hardwoods and corn stover with reduced sulfite loading.

Although a number of biomass pretreatment methods have been studied and proposed, it is worth noting that evaluation and comparison of different biomass pretreatment technologies remains challenging because the pretreatment involves upstream and downstream processes, processing costs, capital investment, chemical recycling, and waste treatment systems. Complete mass balance information during the pretreatment and enzymatic cellulose hydrolysis is the first basic step for comparative efforts (Fig. 1).

\section{References}

1. Lynd, L. R., Laser, M. S., Bransby, D., Dale, B. E., Davison, B., Hamilton, R., et al. (2008). Nature Biotechnology, 26, 169-172.

2. Fortman, J. L., Chhabra, S., Mukhopadhyay, A., Chou, H., Lee, T. S., Steen, E., et al. (2008). Trends in Biotechnology, 26, 375-381.

3. Zhang, Y.-H. P. (2008). Journal of Industrial Microbiology and Biotechnology, 35, 367-375.

4. Wyman, C. E., Dale, B. E., Elander, R. T., Holtzapple, M., Ladisch, M. R., \& Lee, Y. Y. (2005). Bioresource Technology, 96, 1959-1966.

5. Eggeman, T., \& Elander, R. T. (2005). Bioresource Technology, 96, 2019-2025.

6. Lynd, L. R. (1996). Annual Review of Energy and the Environment, 21, 403-465.

7. Sluiter, A., Hames, B., Ruiz, R., Scarlata, C., Sluiter, J., Templeton, D., Crocker, D. (2006). Laboratory analytic procedure LAP-002.

8. Moxley, G., \& Zhang, Y.-H. P. (2007). Energy and Fuels, 21, 3684-3688.

9. Wyman, C. E., Dale, B. E., Elander, R. T., Holtzapple, M., Ladisch, M. R., \& Lee, Y. Y. (2005). Bioresource Technology, 96, 2026-2032.

10. Zhang, Y.-H. P., Schell, D. J., \& McMillan, J. D. (2007). Biotechnology and Bioengineering, 96, 188194.

11. Moxley, G.M., Zhu, Z., \& Zhang, Y.-H.P. (2008). Journal of Agricultural and Food Chemistry. doi:10.1021/jf801303f.

12. Murnen, H. K., Balan, V., Chundawat, S. P. S., Bals, B., daCostaSousa, L., \& Dale, B. E. (2007). Biotechnology Progress, 23, 846-850.

13. Zhang, Y.-H. P., Ding, S.-Y., Mielenz, J. R., Elander, R., Laser, M., Himmel, M., et al. (2007). Biotechnology and Bioengineering, 97, 214-223.

14. Hong, J., Ye, X., \& Zhang, Y. H. P. (2007). Langmuir, 23, 12535-12540.

15. Zhang, Y.-H. P., \& Lynd, L. R. (2004). Biotechnology and Bioengineering, 88, 797-824.

16. Zhang, Y.-H. P., Himmel, M., \& Mielenz, J. R. (2006). Biotechnology Advances, 24, 452-481. 